\title{
Some Common Fixed Point Theorems for Weakly Contractive Maps in G-Metric Spaces
}

\author{
Manoj Kumar* \\ Department of Mathematics Guru Jambheshwar University of Science and Technology, Hisar, India \\ *Corresponding author: manojantil18@gmail.com \\ Received December 05, 2014; Revised January 20, 2015; Accepted January 27, 2015
}

\begin{abstract}
In this paper, first we prove a common fixed point theorem for a pair of weakly compatible maps under weak contractive condition. Secondly, we prove common fixed point theorems for weakly compatible mappings along with E.A. and (CLRf) properties.
\end{abstract}

Keywords: weakly compatible maps, weak contraction, generalized weak contraction, altering distance functions, E.A. property, (CLRf) property

Cite This Article: Manoj Kumar, "Some Common Fixed Point Theorems for Weakly Contractive Maps in GMetric Spaces." Turkish Journal of Analysis and Number Theory, vol. 3, no. 1 (2015): 17-20. doi: 10.12691/tjant3-1-4.

\section{Introduction}

In 2006, Mustafa and Sims [6] introduced a new notion of generalized metric space called G-metric space. In fact, Mustafa et. al. [5-9] studied many fixed point results for a self-mapping in G-metric space under certain conditions.

In the present work, we study some fixed point results for a pair of self mappings in a complete G-metric space $\mathrm{X}$ under weakly contractive conditions related to altering distance functions.

In 1984, Khan et. al. [4] introduced the notion of altering distance function as follows:

Definition 1.1. A mapping f: $[0, \infty) \rightarrow[0, \infty)$ is called an altering distance function if the following properties are satisfied:

$\mathrm{f}$ is continuous and non-decreasing.

$\mathrm{f}(\mathrm{t})=0 \Leftrightarrow \mathrm{t}=0$.

Definition 1.2. Let $X$ be a nonempty set, and let $G: X$ $\times \mathrm{X} \times \mathrm{X} \rightarrow \mathbb{R}_{+}$be a function satisfying the following properties:

(G1) $\mathrm{G}(\mathrm{x}, \mathrm{y}, \mathrm{z})=0$ if $\mathrm{x}=\mathrm{y}=\mathrm{z}$,

(G2) $G(x, x, y)>0$ for all $x, y$ in $X$, with $x \neq y$,

(G3) $G(x, x, y) \leq G(x, y, z)$ for all $x, y, z$ in $X$ with $y \neq$ $\mathrm{Z}$,

(G4) $\mathrm{G}(\mathrm{x}, \mathrm{y}, \mathrm{z})=\mathrm{G}(\mathrm{x}, \mathrm{z}, \mathrm{y})=\mathrm{G}(\mathrm{y}, \mathrm{z}, \mathrm{x})=\ldots$, (symmetry in all three variables),

(G5) $\mathrm{G}(\mathrm{x}, \mathrm{y}, \mathrm{z}) \leq \mathrm{G}(\mathrm{x}, \mathrm{a}, \mathrm{a})+\mathrm{G}(\mathrm{a}, \mathrm{y}, \mathrm{z})$, for all $\mathrm{x}, \mathrm{y}, \mathrm{z}, \mathrm{a}$ in $\mathrm{X}$, (rectangular inequality).

Then the function $G$ is called a generalized metric, or specially a G-metric on $\mathrm{X}$, and the pair $(X, G)$ is called a G-metric space.

Definition 1.3. Let $(X, G)$ be a G-metric space and let $\left\{x_{n}\right\}$ be a sequence of points in $X$, then $\left\{x_{n}\right\}$ is said to be $\mathrm{G}$-convergent to $\mathrm{x}$ in $\mathrm{X}$, if $\mathrm{G}\left(\mathrm{x}, \mathrm{x}_{\mathrm{n}}, \mathrm{x}_{\mathrm{m}}\right) \rightarrow 0$, as $\mathrm{n}, \mathrm{m} \rightarrow \infty$.
G-Cauchy sequence in $\mathrm{X}$, if $\mathrm{G}\left(\mathrm{x}_{\mathrm{n}}, \mathrm{x}_{\mathrm{m}}, \mathrm{x}_{1}\right) \rightarrow 0$, as $\mathrm{n}, \mathrm{m}, \mathrm{l}$ $\rightarrow \infty$.

Proposition 1.4. Let $(\mathrm{X}, \mathrm{G})$ be a G-metric space. Then, the following are equivalent

$\left\{\mathrm{x}_{\mathrm{n}}\right\}$ is G-convergent to $\mathrm{x}$.

$\mathrm{G}\left(\mathrm{x}_{\mathrm{n}}, \mathrm{x}_{\mathrm{n}}, \mathrm{x}\right) \rightarrow 0$, as $\mathrm{n} \rightarrow \infty$.

$\mathrm{G}\left(\mathrm{x}_{\mathrm{n}}, \mathrm{x}, \mathrm{x}\right) \rightarrow 0$, as $\mathrm{n} \rightarrow \infty$.

$\mathrm{G}\left(\mathrm{x}_{\mathrm{n}}, \mathrm{x}_{\mathrm{m}}, \mathrm{x}\right) \rightarrow 0$, as $\mathrm{n}, \mathrm{m} \rightarrow \infty$.

Proposition 1.5. Let $(\mathrm{X}, \mathrm{G})$ be a G-metric space. Then, the following are equivalent the sequence $\left\{\mathrm{x}_{\mathrm{n}}\right\}$ is GCauchy.

for any $\varepsilon>0$ there exists $k$ in $\mathbb{N}$ such that $G\left(x_{n}, x_{m}, x_{m}\right)$ $<\varepsilon$, for all $\mathrm{m}, \mathrm{n} \geq \mathrm{k}$.

Proposition 1.6. Let $(X, G)$ be a G-metric space. Then $\mathrm{f}: \mathrm{X} \rightarrow \mathrm{X}$ is G-continuous at $\mathrm{X}$ in $\mathrm{X}$ if and only if it is Gsequentially continuous at $\mathrm{X}$, that is, whenever $\left\{\mathrm{x}_{\mathrm{n}}\right\}$ is $\mathrm{G}$ convergent to $\mathrm{x},\left\{\mathrm{f}\left(\mathrm{x}_{\mathrm{n}}\right)\right\}$ is G-convergent to $\mathrm{f}(\mathrm{x})$.

Proposition 1.7. Let $(X, G)$ be a G-metric space. Then the function $\mathrm{G}(\mathrm{x}, \mathrm{y}, \mathrm{z})$ is jointly continuous in all three of its variables.

Definition 1.8. A G-metric space (X, G) is called Gcomplete if every G-Cauchy sequence is G-convergent in (X, G).

In 1996, Jungck [3] introduced the concept of weakly compatible maps as follows:

Definition 1.9. Two self maps $f$ and $g$ are said to be weakly compatible if they commute at coincidence points.

In 2002, Aamri et. al. [1] introduced the notion of E.A. property as follows:

Definition 1.10. Two self-mappings $f$ and $g$ of a metric space $(X, d)$ are said to satisfy E.A. property if there exists a sequence $\left\{\mathrm{x}_{\mathrm{n}}\right\}$ in $\mathrm{X}$ such that $\lim _{n \rightarrow \infty} f x_{n}=\lim _{n \rightarrow \infty} g x_{n}=t$ for some $\mathrm{t}$ in $\mathrm{X}$.

In 2011, Sintunavarat et. al. [10] introduced the notion of $\left(\mathrm{CLR}_{\mathrm{f}}\right)$ property as follows:

Definition 1.11. Two self-mappings $f$ and $g$ of a metric space $(X, d)$ are said to satisfy $\left(C L_{f}\right)$ property if there 
exists a sequence $\left\{\mathrm{x}_{\mathrm{n}}\right\}$ in $\mathrm{X}$ such that $\lim _{n \rightarrow \infty} f x_{n}=\lim _{n \rightarrow \infty} g x_{n}=f x$ for some $\mathrm{x}$ in $\mathrm{X}$.

In 2011, Aydi H. [2] introduced the concept of weak contraction in G-metric space as follows:

Definition 1.12. Let $(X, G)$ be a G-metric space. A mapping $\mathrm{f}: \mathrm{X} \rightarrow \mathrm{X}$ is said to be a $\varphi$-weak contraction, if there exists a map $\varphi:[0, \infty) \rightarrow[0, \infty)$ with $\varphi(0)=0$ and $\varphi(\mathrm{t})>0$ for all $\mathrm{t}>0$ such that

$\mathrm{G}(\mathrm{fx}, \mathrm{fy}, \mathrm{fz}) \leq \mathrm{G}(\mathrm{x}, \mathrm{y}, \mathrm{z})-\varphi(\mathrm{G}(\mathrm{x}, \mathrm{y}, \mathrm{z}))$, for all $\mathrm{x}, \mathrm{y}, \mathrm{z}$ in $\mathrm{X}$.

In 2011, Aydi H. [2] proved the following result:

Theorem 1.13. Let $X$ be a complete G-metric space. Suppose the map $\mathrm{f}: \mathrm{X} \rightarrow \mathrm{X}$ satisfies the following:

$\psi(\mathrm{G}(\mathrm{fx}, \mathrm{fy}, \mathrm{fz})) \leq \psi(\mathrm{G}(\mathrm{x}, \mathrm{y}, \mathrm{z}))-\varphi(\mathrm{G}(\mathrm{x}, \mathrm{y}, \mathrm{z}))$, for all $\mathrm{x}, \mathrm{y}, \mathrm{z}$ in $\mathrm{X}$,

where $\psi$ and $\varphi$ are altering distance functions.

Then $\mathrm{f}$ has a unique fixed point (say $\mathrm{u}$ ) and $\mathrm{f}$ is Gcontinuous at $\mathrm{u}$.

\section{Weakly Compatible Maps}

Theorem 2.1. Let $(X, G)$ be a G-metric space and let $f$ and $\mathrm{g}$ be self mappings on $\mathrm{X}$ satisfying the followings:

$$
g X \subset f X
$$

$f X$ or $g X$ is complete subspace of $X$,

$\psi(G(g x, g y, g z))$

$\leq \psi(G(f x, f y, f z))-\varphi(G(f x, f y, f z)$,

where and are altering dis $\tan c e$ functions.

Then, $f$ and $g$ have a point of coincidence in $X$.

Moreover, if $f$ and $g$ are weakly compatible, then $f$ and $\mathrm{g}$ have a unique common fixed point.

Proof. Let $\mathrm{x}_{0} \in \mathrm{X}$. From (2.1), we can construct sequences $\left\{\mathrm{x}_{\mathrm{n}}\right\}$ and $\left\{\mathrm{y}_{\mathrm{n}}\right\}$ in $\mathrm{X}$ by $\mathrm{y}_{\mathrm{n}}=\mathrm{fx}_{\mathrm{n}+1}=\mathrm{gx}_{\mathrm{n}}, \mathrm{n}=0,1$, $2, \ldots$

From (2.3), we have

$\psi\left(G\left(y_{n}, y_{n+1}, y_{n+1}\right)\right)=\psi\left(G\left(g x_{n}, g x_{n+1}, g x_{n+1}\right)\right)$

$\leq \psi\left(G\left(f x_{n}, f x_{n+1}, f x_{n+1}\right)\right)-\varphi\left(G\left(f x_{n}, f x_{n+1}, f x_{n+1}\right)\right)$

$=\psi\left(G\left(y_{n-1}, y_{n}, y_{n}\right)\right)-\varphi\left(G\left(y_{n-1}, y_{n}, y_{n}\right)\right)$

$<\psi\left(G\left(y_{n-1}, y_{n}, y_{n}\right)\right)$.

Since $\psi$ is non-decreasing, therefore we have

$$
G\left(y_{n}, y_{n+1}, y_{n+1}\right) \leq G\left(y_{n-1}, y_{n}, y_{n}\right) .
$$

Let $u_{n}=G\left(y_{n}, y_{n+1}, y_{n+1}\right)$, then $0 \leq u_{n} \leq u_{n-1}$ for all $n>0$.

It follows that the sequence $\left\{u_{n}\right\}$ is monotonically decreasing and bounded below. So, there exists some $r \geq 0$ such that

$$
\lim _{n \rightarrow \infty} G\left(y_{n+1}, y_{n}, y_{n}\right)=\lim _{n \rightarrow \infty} u_{n}=r .
$$

From (2.4) and (2.5) and letting $\mathrm{n} \rightarrow \infty$, we have $\psi(\mathrm{r}) \leq \psi(\mathrm{r})-\varphi(\mathrm{r})$, since $\psi$ and $\varphi$ are continuous.

Thus, we get $\varphi(\mathrm{r})=0$, i.e., $\mathrm{r}=0$, by property of $\varphi$, we have

$$
\lim _{n \rightarrow \infty} G\left(y_{n+1}, y_{n}, y_{n}\right)=\lim _{n \rightarrow \infty} u_{n}=0 .
$$

Now, we prove that $\left\{\mathrm{y}_{\mathrm{n}}\right\}$ is a G-Cauchy sequence. Let, if possible, $\left\{\mathrm{y}_{\mathrm{n}}\right\}$ is not a G-Cauchy sequence. Then, there exists $\varepsilon>0$, for which, we can find subsequences $\left\{\mathrm{y}_{\mathrm{m}(\mathrm{k})}\right\}$ and $\left\{\mathrm{y}_{\mathrm{n}(\mathrm{k})}\right\}$ of $\left\{\mathrm{y}_{\mathrm{n}}\right\}$ with $\mathrm{n}(\mathrm{k})>\mathrm{m}(\mathrm{k})>\mathrm{k}$ such that

$$
G\left(y_{n(k)}, y_{m(k)}, y_{m(k)}\right) \geq \varepsilon
$$

Let $\mathrm{m}(\mathrm{k})$ be the least positive integer exceeding $\mathrm{n}(\mathrm{k})$ satisfying (3.7) such that

$$
\begin{aligned}
& G\left(y_{n(k)-1}, y_{m(k)}, y_{m(k)}\right)<\varepsilon, \\
& \text { for every int eger } k .
\end{aligned}
$$

Then, we have

$$
\begin{aligned}
& \varepsilon \leq G\left(y_{n(k)}, y_{m(k)}, y_{m(k)}\right) \\
& \leq G\left(y_{n(k)}, y_{n(k)-1}, y_{n(k)-1}\right)+G\left(y_{n(k)-1}, y_{m(k)}, y_{m(k)}\right) \\
& <\varepsilon+G\left(y_{n(k)}, y_{n(k)-1}, y_{n(k)-1}\right) .
\end{aligned}
$$

Letting $\mathrm{k} \rightarrow \infty$, and using (2.6), we have

$$
\lim _{k \rightarrow \infty} G\left(y_{n(k)}, y_{n(k)-1}, y_{n(k)-1}\right)=0 \text {. }
$$

From (2.8), we get

$$
\lim _{k \rightarrow \infty} G\left(y_{n(k)}, y_{m(k)}, y_{m(k)}\right)=\varepsilon .
$$

Moreover, we have

$G\left(y_{n(k)}, y_{m(k)}, y_{m(k)}\right)$

$\leq G\left(y_{n(k)}, y_{n(k)-1}, y_{n(k)-1}\right)+G\left(y_{n(k)-1}, y_{m(k)-1} y_{m(k)-1}\right)$

$+G\left(y_{m(k)-1}, y_{m(k)}, y_{m(k)}\right)$,

$G\left(y_{n(k)-1}, y_{m(k)-1}, y_{m(k)-1}\right)$

$\leq G\left(y_{n(k)-1}, y_{n(k)}, y_{n(k)}\right)+G\left(y_{n(k)}, y_{m(k)}, y_{m(k)}\right)$

$+G\left(y_{m(k)}, y_{m(k)-1}, y_{m(k)-1}\right)$.

Letting $\mathrm{k} \rightarrow \infty$ in the above two inequalities and using $(2.6)-(2.10)$, we get

$$
\lim _{k \rightarrow \infty} G\left(y_{n(k)-1}, y_{m(k)-1}, y_{m(k)-1}\right)=\varepsilon .
$$

Taking $\mathrm{x}=\mathrm{x}_{\mathrm{n}(\mathrm{k})}, \mathrm{y}=\mathrm{x}_{\mathrm{m}(\mathrm{k})}$ and $\mathrm{z}=\mathrm{x}_{\mathrm{m}(\mathrm{k})}$ in (2.3), we get

$$
\begin{aligned}
& \psi\left(G\left(y_{n(k)}, y_{m(k)}, y_{m(k)}\right)\right) \\
& =\psi\left(G\left(g x_{n(k)}, g x_{m(k)}, g x_{m(k)}\right)\right) \\
& \leq \psi\left(G\left(f x_{n(k)}, f x_{m(k)}, f x_{m(k)}\right)\right) \\
& -\varphi\left(G\left(f x_{n(k)}, f x_{m(k)}, f x_{m(k)}\right)\right) \\
& =\psi\left(G\left(y_{n(k)-1}, y_{m(k)-1}, y_{m(k)-1}\right)\right) \\
& -\varphi\left(G\left(y_{n(k)-1}, y_{m(k)-1}, y_{m(k)-1}\right)\right)
\end{aligned}
$$


Letting $\mathrm{k} \rightarrow \infty$, using (2.11) and the continuity of $\psi$ and $\varphi$, we get

$\psi(\varepsilon) \leq \psi(\varepsilon)-\varphi(\varepsilon)$, that is, $\varphi(\varepsilon)=0$, a contradiction, since $\varepsilon>0$.

Thus $\left\{\mathrm{y}_{\mathrm{n}}\right\}$ is a G-Cauchy sequence.

Since $\mathrm{fX}$ is complete subspace of $\mathrm{X}$, so there exists a point $\mathrm{u} \in \mathrm{fX}$, such that

$$
\lim _{n \rightarrow \infty} y_{n}=\lim _{n \rightarrow \infty} f x_{n+1}=u
$$

Now, we show that $u$ is the common fixed point of $f$ and $\mathrm{g}$.

Since $\mathrm{u} \in \mathrm{fX}$, so there exists a point $\mathrm{p} \in \mathrm{X}$, such that, $\mathrm{fp}=\mathrm{u}$.

From (2.3), we have

$$
\begin{aligned}
& \psi(G(f p, g p, g p))=\lim _{n \rightarrow \infty} \psi\left(G\left(g x_{n}, g p, g p\right)\right) \\
& \leq \lim _{n \rightarrow \infty} \psi\left(G\left(f x_{n}, f p, f p\right)\right)-\lim _{n \rightarrow \infty} \varphi\left(G\left(f x_{n}, f p, f p\right)\right) .
\end{aligned}
$$

Using (2.12) and the property of $\psi$ and $\varphi$, we have $\psi(\mathrm{G}(\mathrm{fp}, \mathrm{gp}, \mathrm{gp})) \leq \psi(0)-\varphi(0)$, implies that, $\mathrm{G}(\mathrm{fp}$, $\mathrm{gp}, \mathrm{gp})=0$, that is, $\mathrm{fp}=\mathrm{gp}=\mathrm{u}$.

Hence $u$ is the coincidence point of $f$ and $g$.

Since, $f p=g p$, and $f, g$ are weakly compatible, we have $\mathrm{fu}=\mathrm{fgp}=\mathrm{gfp}=\mathrm{gu}$.

Now, we claim that, $\mathrm{fu}=\mathrm{gu}=\mathrm{u}$.

Let, if possible, gu $\neq u$.

From (2.3), we have

$$
\begin{aligned}
& \psi(G(g u, u, u))=\psi(G(g u, g p, g p)) \\
& \leq \psi(G(f u, f p, f p))-\varphi(G(f u, f p, f p)) \\
& =\psi(G(g u, u, u))-\varphi(G(g u, u, u)) \\
& <\psi(G(g u, u, u)), \text { a contradiction. }
\end{aligned}
$$

Hence $g u=u=f u$, so $u$ is the common fixed point of $f$ and $\mathrm{g}$.

For the uniqueness, let $\mathrm{v}$ be another common fixed point of $f$ and $g$ so that $f v=g v=v$.

We claim that $\mathrm{u}=\mathrm{v}$. Let, if possible, $\mathrm{u} \neq \mathrm{v}$.

From (2.3), we have

$$
\begin{aligned}
& \psi(G(u, v, v))=\psi(G(g u, g v, g v)) \\
& \leq \psi(G(f u, f v, f v))-\varphi(G(f u, f v, f v)) \\
& =\psi(G(u, v, v))-\varphi(G(u, v, v)) \\
& <\psi(G(u, v, v)), \text { a contradiction. }
\end{aligned}
$$

Thus, we get, $\mathrm{u}=\mathrm{v}$.

Hence $u$ is the common fixed point of $f$ and $g$.

\section{E.A. Property}

Theorem 3.1. Let $(X, G)$ be a G-metric space. Let $f$ and $\mathrm{g}$ be weakly compatible self maps of $\mathrm{X}$ satisfying (2.3) and the followings:

$f$ and $g$ satisfy the E.A. property,

$f X$ is closed subset of $X$.
Then $\mathrm{f}$ and $\mathrm{g}$ have a unique common fixed point

Proof. Since $f$ and g satisfy the E.A. property, there exists a sequence $\left\{x_{n}\right\}$ in $X$ such that

$\lim _{n \rightarrow \infty} \mathrm{gx}_{\mathrm{n}}=\lim _{n \rightarrow \infty} \mathrm{fx}_{\mathrm{n}}=\mathrm{x}_{0}$ for some $\mathrm{x}_{0}$ in $\mathrm{X}$.

Now, $\mathrm{XX}$ is closed subset of $\mathrm{X}$, therefore, by (3.1), we have $\lim _{n \rightarrow \infty} \mathrm{fx}_{\mathrm{n}}=\mathrm{fz}$, for some $\mathrm{z}$ in $\mathrm{X}$.

From (2.3), we have

$$
\begin{aligned}
& \psi\left(G\left(g x_{n}, g z, g z\right)\right) \leq \psi\left(G\left(f x_{n}, f z, f z\right)\right) \\
& -\varphi\left(G\left(f x_{n}, f z, f z\right)\right)
\end{aligned}
$$

Letting limit as $\mathrm{n} \rightarrow \infty$, we have

$$
\begin{aligned}
& \lim _{n \rightarrow \infty} \psi\left(G\left(g x_{n}, g z, g z\right)\right) \leq \lim _{n \rightarrow \infty} \psi\left(G\left(f x_{n}, f z, f z\right)\right) \\
& -\lim _{n \rightarrow \infty} \varphi\left(G\left(f x_{n}, f z, f z\right)\right) .
\end{aligned}
$$

Using (2.3), and property of $\psi, \varphi$, we have

$\psi(\mathrm{G}(\mathrm{fz}, \mathrm{gz}, \mathrm{gz})) \leq \psi(0)-\varphi(0)=0$, implies that, $\mathrm{G}(\mathrm{fz}$, $\mathrm{gz}, \mathrm{gz})=0$, that is, $\mathrm{fz}=\mathrm{gz}$.

Now, we show that $\mathrm{gz}$ is the common fixed point of $\mathrm{f}$ and $\mathrm{g}$.

Suppose that $g z \neq$ ggz. Since $\mathrm{f}$ and $\mathrm{g}$ are weakly compatible, $g f z=$ fgz and therefore $f f a=$ gga.

From (2.3), we have

$$
\begin{aligned}
& \psi(G(g z, g g z, g g z)) \\
& \leq \psi(G(f z, f g z, f g z))-\varphi(G(f z, f g z, f g z)) \\
& =\psi(G(g z, g g z, g g z))-\varphi(G(g z, g g z, g g z)) \\
& <\psi(G(g z, g g z, g g z)), \text { a contradiction. }
\end{aligned}
$$

Hence $g g z=g z$, so $g z$ is the common fixed point of $f$ and $\mathrm{g}$.

Finally, we show that the fixed point is unique.

Let $u$ and $v$ be two common fixed points of $f$ and $g$ such that $\mathrm{u} \neq \mathrm{v}$.

From (2.3), we have

$$
\begin{aligned}
& \psi(G(u, v, v))=\psi(G(g u, g v, g v)) \\
& \leq \psi(G(f u, f v, f v))-\varphi(G(f u, f v, f v)) \\
& =\psi(G(u, v, v))-\varphi(G(u, v, v)) \\
& <\psi(G(u, v, v)), \text { a contradiction. }
\end{aligned}
$$

Thus, we get, $\mathrm{u}=\mathrm{v}$.

Hence $u$ is the unique common fixed point of $f$ and $g$.

\section{4. $\left(\mathrm{CLR}_{\mathrm{f}}\right)$ Property}

Theorem 4.1. Let $(X, G)$ be a G-metric space. Let $f$ and $\mathrm{g}$ be weakly compatible self maps of $\mathrm{X}$ satisfying (2.3) and the following:

$$
f \text { and } g \text { satisfy }\left(C L R_{f}\right) \text { property. }
$$

Then $\mathrm{f}$ and $\mathrm{g}$ have a unique common fixed point.

Proof. Since $f$ and $g$ satisfy the $\left(\mathrm{CLR}_{\mathrm{f}}\right)$ property, there exists a sequence $\left\{x_{n}\right\}$ in $X$ such that

$\lim _{n \rightarrow \infty} \mathrm{gx}_{\mathrm{n}}=\lim _{n \rightarrow \infty} \mathrm{fx}_{\mathrm{n}}=\mathrm{fx}$ for some $\mathrm{x}$ in $\mathrm{X}$.

From (2.3), we have 


$$
\begin{aligned}
& \psi\left(G\left(g x_{n}, g x, g x\right)\right) \\
& \leq \psi\left(G\left(f x_{n}, f x, f x\right)\right)-\varphi\left(G\left(f x_{n}, f x, f x\right)\right) .
\end{aligned}
$$

Letting limit as $\mathrm{n} \rightarrow \infty$, we have

$$
\begin{aligned}
& \lim _{n \rightarrow \infty} \psi\left(G\left(g x_{n}, g x, g x\right)\right) \\
& \leq \lim _{n \rightarrow \infty} \psi\left(G\left(f x_{n}, f x, f x\right)\right)-\lim _{n \rightarrow \infty} \varphi\left(G\left(f x_{n}, f x, f x\right)\right) .
\end{aligned}
$$

Using (2.3), and property of $\psi, \varphi$, we have

$\psi(\mathrm{G}(\mathrm{fz}, \mathrm{gz}, \mathrm{gz})) \leq \psi(0)-\varphi(0)=0$, implies that, $\mathrm{G}(\mathrm{fx}$, $\mathrm{gx}, \mathrm{gx})=0$, that is, $\mathrm{fx}=\mathrm{gx}$.

Let $\mathrm{w}=\mathrm{fx}=\mathrm{gx}$.

Since $f$ and $g$ are weakly compatible, $g f x=f g x$, implies that, $f w=f g x=g f x=g w$.

Now, we claim that $\mathrm{gw}=\mathrm{w}$.

Let, if possible, $\mathrm{gw} \neq \mathrm{w}$.

From (2.3), we have

$$
\begin{aligned}
& \psi(G(g w, w, w))=\psi(G(g w, g x, g x)) \\
& \leq \psi(G(f w, f x, f x))-\varphi(G(f w, f x, f x)) \\
& =\psi(G(g w, w, w))-\varphi(G(g w, w, w)) \\
& <\psi(G(g w, w, w)), \text { a contradiction. }
\end{aligned}
$$

Hence $\mathrm{gw}=\mathrm{w}=\mathrm{fw}$, so $\mathrm{w}$ is the common fixed point of $f$ and $g$.

Finally, we show that the fixed point is unique.

Let $\mathrm{v}$ be another common fixed point of $\mathrm{f}$ and $\mathrm{g}$ such that $\mathrm{fv}=\mathrm{v}=\mathrm{gv}$.

From (2.3), we have

$$
\begin{aligned}
& \psi(G(w, v, v))=\psi(G(g w, g v, g v)) \\
& \leq \psi(G(f w, f v, f v))-\varphi(G(f w, f v, f v)) \\
& =\psi(G(w, v, v))-\varphi(G(w, v, v)) \\
& <\psi(G(w, v, v)), \text { a contradiction. }
\end{aligned}
$$

Thus, we get, $\mathrm{w}=\mathrm{v}$.

Hence $w$ is the unique common fixed point of $f$ and $g$.

Example 4.2. Let $X=[0,1]$ and $G(x, y, z)=\max \{|x-y|$, $|y-z|,|x-z|\}$, for all $x, y, z$ in $X$. Clearly $(X, G)$ is a Gmetric space.

Let $\mathrm{fx}=\frac{1}{4} \mathrm{x}$ and $\mathrm{gx}=\frac{1}{8} \mathrm{x}$ for each $\mathrm{x} \in \mathrm{X}$. Then

$$
g X=\left[0, \frac{1}{8}\right]\left[0, \frac{1}{4}\right]=f X .
$$

Without loss of generality, assume that $x>y>z$. Then, $\mathrm{G}(\mathrm{x}, \mathrm{y}, \mathrm{z})=|\mathrm{x}-\mathrm{z}|$.

Let $\psi(\mathrm{t})=5 \mathrm{t}$ and $\varphi(\mathrm{t})=\mathrm{t}$. Then

$$
\begin{aligned}
& \psi(G(g x, g y, g z))=\psi\left(\frac{1}{8}|x-z|\right) \\
& =5 \frac{1}{8}|x-z|=\frac{5}{8}|x-z| . \\
& \psi(G(f x, f y, f z))=\psi\left(\frac{1}{4}|x-z|\right)=\frac{5}{4}|x-z| . \\
& \varphi(G(f x, f y, f z))=\varphi\left(\frac{1}{4}|x-z|\right)=\frac{1}{4}|x-z| .
\end{aligned}
$$

From here, we have

$$
\psi(G(f x, f y, f z))-\varphi(G(f x, f y, f z))=|x-z| .
$$

So $\psi(\mathrm{G}(\mathrm{gx}, \mathrm{gy}, \mathrm{gz}))<\psi(\mathrm{G}(\mathrm{fx}, \mathrm{fy}, \mathrm{fz}))-\varphi(\mathrm{G}(\mathrm{fx}, \mathrm{fy}$, fz)).

From here, we conclude that $\mathrm{f}$, g satisfy the relation (2.3)

Consider the sequence $\left\{\mathrm{x}_{\mathrm{n}}\right\}=\left\{\frac{1}{n}\right\}$ so that $\lim _{n \rightarrow \infty} f x_{n}=\operatorname{im}_{n \rightarrow \infty} g x_{n}=0=f(0)$, hence the pair (f, g) satisfy the $\left(\mathrm{CLR}_{\mathrm{f}}\right)$ property. Also, $\mathrm{f}$ and $\mathrm{g}$ are weakly compatible and 0 is the unique common fixed point of $f$ and $\mathrm{g}$.

From here, we also deduce that $\lim _{n \rightarrow \infty} f x_{n}=\operatorname{im}_{n \rightarrow \infty} g x_{n}=0$, where $0 \in \mathrm{X}$, implies that $\mathrm{f}$ and $\mathrm{g}$ satisfy E.A. property.

\section{References}

[1] Aamri M. and Moutawakil D. El., Some new common fixed point theorems under strict contractive conditions, J. Math. Anal. Appl. 270, 181-188, 2002.

[2] Aydi H., A fixed point result involving a generalized weakly contractive condition in G-metric spaces, Bulletin of Mathematical Analysis and Applications, vol. 3 Issue 4 (2011), 180-188.

[3] Jungck G., Common fixed points for non-continuous non-self mappings on non-metric spaces, Far East J. Math. Sci. 4 (2), (1996), 199-212.

[4] Khan M.S., Swaleh M. and Sessa S., Fixed point theorems for altering distances between the points, Bull. Aust. Math. Soc. 30 (1) (1984), 1-9.

[5] Mustafa Z. and Sims B., Some remarks concerning D-metric spaces, in Proceedings of the International Conference on Fixed Point Theory and Applications, pp. 189-198, Yokohama, Japan, 2004.

[6] Mustafa Z. and Sims B., A new approach to generalized metric spaces, J. Nonlinear and Convex Anal. 7 (2) (2006), 289-297.

[7] Mustafa Z., Obiedat H., and Awawdeh F., Some fixed point theorem for mapping on complete G-metric spaces, Fixed Point Theory Appl. Volume 2008, Article ID 189870, 12 pages, 2008.

[8] Mustafa Z., Shatanawi W. and Bataineh M., Existence of fixed point results in G-metric spaces, International J. Math. Math. Sciences, vol. 2009, Article ID 283028, 10 pages, 2009.

[9] Mustafa Z. and Sims B., Fixed point theorems for contractive mappings in complete G-metric spaces, Fixed Point Theory Appl. vol. 2009, Article ID 917175, 10 pages, 2009.

[10] Sintunavarat W. and Kumam P., Common Fixed Point Theorems for a Pair of Weakly Compatible mappings in Fuzzy Metric Spaces, Hindawi Publishing Corporation, Journal of Applied mathematics, vol. 2011, Article ID 637958, 14 pages. 